\title{
Effects of Attrition and Ball Milling on the Properties of Magnesium Diboride
}

\author{
C E J Dancer ${ }^{1}$, D Prabhakaran ${ }^{2}$, A Crossley ${ }^{1}$, R I Todd $^{1}$ and C R M Grovenor ${ }^{1}$ \\ ${ }^{1}$ Department of Materials, University of Oxford, Parks Road, Oxford, OX1 3PH, UK \\ ${ }^{2}$ Department of Physics, University of Oxford, Clarendon Laboratory, Parks Road, Oxford, \\ OX1 3PU, UK
}

Email: claire.dancer@materials.ox.ac.uk

\begin{abstract}
Commercially produced magnesium diboride powder was modified by attrition milling and ball milling in propan-2-ol for various durations. These powders were characterized by particle size distribution measurements using laser diffraction, impurity analysis by X-ray diffraction, energy dispersive spectroscopy and X-ray photoelectron spectroscopy, and by scanning electron microscopy, and were then used to produce magnesium diboride samples by pressureless heat-treatment at peak temperatures up to $1100{ }^{\circ} \mathrm{C}$. X-ray diffraction, scanning electron microscopy, Vickers hardness measurements, and density measurements using the Archimedes method were carried out to characterize the properties of the samples, as well as determination of their superconducting properties using the magnetization method. Magnesium diboride produced from powder milled under some conditions had higher $J_{c, \text { mag }}$ than those produced from as-purchased powder, but the relationship between milling duration or energy and superconducting performance is a complex one, affected by both particle size and impurity content of the starting powder.
\end{abstract}

\section{Introduction}

Superconductivity in magnesium diboride was first reported in 2001 by Nagmatsu et al [1] and since then magnesium diboride thin films, wires and tapes have all been produced by both the in situ method, using various precursors, and the ex situ method using $\mathrm{MgB}_{2}$ powder [24]. In situ processing techniques allow greater control of the doping levels and grain size of the final microstructure by varying the precursors. However the large density change from $2.10 \mathrm{~g} \mathrm{~cm}^{-3}$ for a mixture of $\mathrm{Mg}$ and $\mathrm{B}$ powders to $2.63 \mathrm{~g} \mathrm{~cm}^{-3}$ for $\mathrm{MgB}_{2}$ which occurs during heat-treatment [5] and consequent porosity means that the ex situ processing route is preferred for industrial production of powder-in-tube (PIT) wires by at least one major manufacturer $[6,7,8]$.

Good quality $\mathrm{MgB}_{2}$ powder for ex situ processing can be produced in-house [9], but the majority of published studies have used commercially produced $\mathrm{MgB}_{2}$ powder, particularly that source from Alfa Aesar. However the impurity levels of these powders vary from batch to batch [10] and have relatively large particle size distributions, containing some particles up to $100 \mu \mathrm{m}$ in size $[4,11]$. Several researchers have attempted to improve the powder by milling prior to artefact production. Flukiger et al [11] compared PIT wires produced from aspurchased Alfa Aesar powder and the same powder following milling in isopropanol for 2 hours, and found an improvement in critical current density, $J_{c}$, though not in upper critical field, $\mu_{0} H_{c 2}$. In a later paper by the same group, it is argued that the reason for this improvement is not the changes in the particle size but rather due to increased carbon and 
oxygen impurity levels at the grain boundaries [3]. For longer milling times (up to 100 hours) $J_{c}$ decreased suggesting a critical ball milling duration to optimise $J_{c}$. Senkowicz et al [12] showed that deliberate addition of low levels of carbon by milling $\mathrm{MgB}_{2}$ powder with carbon enhances both $J_{c}$ and $\mu_{0} H_{c 2}$, while adding larger amounts leads to a decrease in these properties, consistent with the known effects of carbon doping.

Grovenor et al [13] used electron microprobe analysis to determine the oxygen levels in the cores of PIT wires produced from as-purchased and milled Alfa Aesar powders. A marked decrease in $J_{c}$ for the wire produced from milled powder was observed, along with a large increase in oxygen content in the core. This powder was milled in air, which accounts for the high level of oxygen observed in accordance with the observations of Senkowicz et al [14] for $\mathrm{MgB}_{2}$ samples with varying degrees of exposure to air. Goldacker et al [4] and Chen et al [15] also saw a decrease in $J_{c}$ for samples produced from powders prepared from Alfa Aesar $\mathrm{MgB}_{2}$ by high energy attrition milling and planetary ball milling respectively. Conversely, a series of papers using $\mathrm{MgB}_{2}$ powder synthesised in-house indicate a monotonically increasing relationship between $J_{c}$ and both milling time and milling speed [8-9, 16-18]. There are no reports in the literature to the authors' knowledge which compare the effects of different milling procedures, and as often only the milling duration is given without the milling speed or details of the reduction in particle size, it is difficult to classify the various reports into "short" milling processes which are shown by Vignolo et al [17] to enhance $J_{c}$ and "long" milling processes which decrease it.

In a previous study [19], we showed how the particle size distribution of as-purchased Alfa Aesar $\mathrm{MgB}_{2}$ powder dispersed in propan-2-ol measured by laser diffraction varied depending on the preparation method. Powder which had been ultrasonically dispersed in propan-2-ol had a significantly smaller average particle size compared to non-dispersed powder, indicating that the fundamental average particle size of the powder was in fact smaller than previous observations had suggested. This manuscript extends this technique to examine both powders which have been subjected to ball milling (for various durations) and those subjected to attrition milling, again dispersed using a range of methods. We describe the changes in the particle size distributions and impurity levels of the powders, and examine the effect of these on the microstructure and superconducting properties of bulk $\mathrm{MgB}_{2}$ samples prepared from these powders, in order to establish the suitability of these protocols for $\mathrm{MgB}_{2}$ PIT wire manufacture.

\section{Experimental methods}

All of the modified powders studied in this work were prepared from Alfa Aesar $\mathrm{MgB}_{2}$ powder (98\% purity, -325 mesh). Characterization of this starting powder, including particle size distribution and morphology, was discussed in an earlier paper [19]. The batch of $\mathrm{MgB}_{2}$ powder used for these samples has a $\theta-2 \theta$ X-ray diffraction (XRD) spectrum consisting solely of peaks attributable to the $\mathrm{MgB}_{2}$ phase, indicating an impurity content of less than $5 \%$.

Dry milling leads to agglomeration of particles [3] and increased oxygen levels [13], so propan-2-ol was used as the milling medium. We showed using the sedimentation technique described by Pryor [20] that propan-2-ol has good dispersive properties compared to other media. The weight fraction of particles with Stokes's diameter $d_{\text {Stokes }}>10 \mu \mathrm{m}$ was measured after allowing magnesium diboride to sediment in methanol, ethanol, propan-2-ol, 2-butanol, acetone, cyclohexane, and ethylene glycol for the appropriate time calculated using Stokes's Law (Table 1). Using this method, it was clear that the alcohols caused the least agglomeration as dispersion in these liquids obtained the highest fraction of particles with small $d_{\text {Stokes }}$ and so propan-2-ol was chosen in order to allow comparison with the work of Flukiger et al [3,11]. Water could not be used due its reactivity with $\mathrm{MgB}_{2}$ [21]. 
Table 1. Weight fraction of as-purchased $\mathrm{MgB}_{2}$ powder with $d_{\text {Stokes }}<10 \mu \mathrm{m}$ in various liquids. Higher weight fraction of material with $d_{\text {Stokes }}<10 \mu \mathrm{m}$ indicates a higher degree of dispersion, which is required for efficient ball milling.

\begin{tabular}{cc}
\hline Liquid & $\begin{array}{c}\text { Weight Fraction of Material with } \\
d_{\text {Stokes }}<10 \mu \mathrm{m}\end{array}$ \\
\hline Methanol & $38 \%$ \\
\hline Ethanol & $42 \%$ \\
\hline Butan-2-ol & $38 \%$ \\
\hline Propan-2-ol & $38 \%$ \\
\hline Cyclohexane & $0 \%$ \\
\hline Acetone & $2 \%$ \\
\hline
\end{tabular}

The optimum solid loading during the milling processes occurs when the powder loading is sufficient to give efficient average particle size reduction [22] but the concentration is still low enough that the viscosity is not increased sufficiently to restrict the powder-liquid slurry flowing easily in the ball milling container [23]. In low solid concentration slurries, energy is wasted by ball-on-ball collisions which do not break up the powder particles; in slurries with high solid loading the viscosity is increased significantly, so that the liquid itself absorbs some of the milling and energy and damps the motion of the milling media. Measurements of the viscosity of $\mathrm{MgB}_{2}$ /propan-2-ol slurries of various concentrations were made using a Gallenkamp Torsion Viscometer (VHA-200-M, cylinder size 3) (Figure 1). The optimum solid loading is the concentration just below that where the viscosity rises above the plateau level for low solid loading, this being where the two factors described above are balanced.

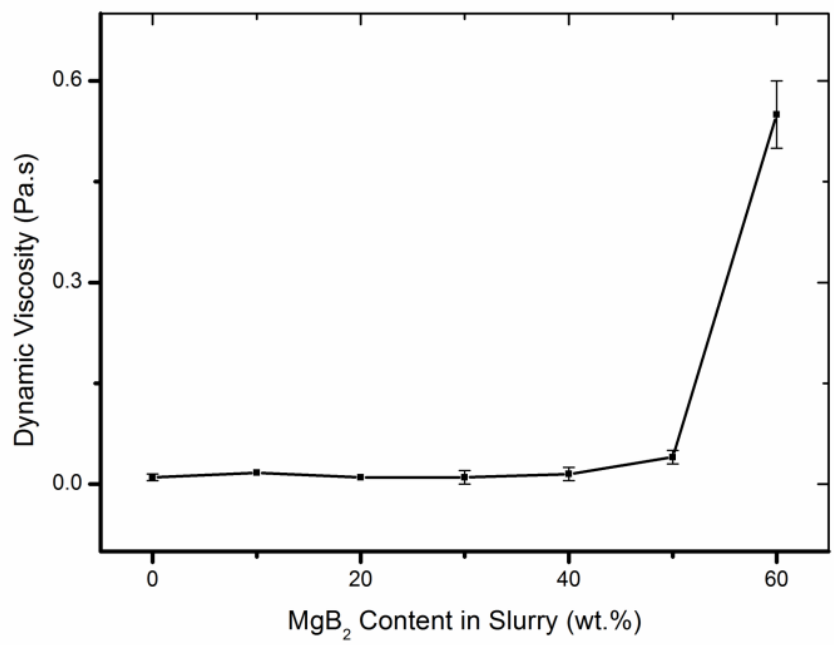

Figure 1. Viscosity of commercial magnesium diboride powder dispersed in propan-2-ol

Ball milling was carried out in sealed $250 \mathrm{ml}$ polyethylene jars using propan-2-ol as a dispersion medium and ytttria-stabilized zirconia (YSZ) milling media (Inframat Advanced Materials; cylindrical, $10 \mathrm{~mm}$ diameter, $10 \mathrm{~mm}$ height). Milling was carried out for durations between $1 \mathrm{~h}-20 \mathrm{~h}$. Bottles were packed either in nitrogen or in ambient air to compare the effect of milling in different atmospheres. Attrition milling was carried out using a commercially available attrition mill (Union Process Szegardi Attritor System Model 01HD) fitted with YSZ tank and blade. Spherical YSZ milling media (Inframat Advanced Materials; $3 \mathrm{~mm}$ diameter beads) were used to facilitate stirring in the mill. A slurry of magnesium diboride powder in propan-2-ol prepared only in air was milled for $2 \mathrm{~h}$ at $500 \mathrm{rpm}$.

After milling the propan-2-ol was removed from the slurry by evaporation on a hotplate in air or in a nitrogen glovebox. The particle size was measured using laser diffraction (Malvern Mastersizer), and the powder was also examined using a scanning electron microscope (SEM) (JEOL 840F). XRD spectra (using a Philips $\theta-2 \theta$ diffractometer with $\mathrm{Cu}-$ 
$\mathrm{K} \alpha$ radiation generated at $35 \mathrm{kV}$ and $50 \mathrm{~mA}$ ) and $\mathrm{X}$-ray photoemission spectra (using a VG nine channel CLAM4 electron energy analyser at a base pressure of $5 \times 10^{-10}$ torr and $300 \mathrm{~W}$ unmonochromated $\mathrm{Mg} \mathrm{X}$-ray excitation) were taken to establish the effect of milling on the impurity content of the powders. XRD spectra were analysed using the Philips X'Pert Highscore software, and the XPS spectra using CASA XPS. For XPS spectra, the analyser was operated at constant pass energy of $100 \mathrm{eV}$ for wide scans and $20 \mathrm{eV}$ for detailed scans, setting the $\mathrm{C} 1 \mathrm{~s}$ peak to be at $284.8 \mathrm{eV}$. Peak areas were measured after background subtraction following methods of Shirley [24]. The area under the principal peak of each element in the spectrum, divided by an empirically derived sensitivity factor [25], is proportional to the concentration of that element on the surface (approximately the top 10 $\mathrm{nm}$ ). The sensitivity of the technique is around 0.1 at.\%, depending on the element [26].

$\mathrm{MgB}_{2}$ samples were produced from the processed powders by uniaxial pressing in a stainless steel die at $10 \mathrm{MPa}$ pressure followed by heat-treatment in flowing argon gas (BOC, $99.995 \%$ purity) at $950{ }^{\circ} \mathrm{C}$ or $1100{ }^{\circ} \mathrm{C}$ for $1 \mathrm{~h}$. The lower temperature was chosen as it is typical of heat-treatment temperatures used for $\mathrm{MgB}_{2}$ ex situ PIT wires [27, 28]. The higher temperature was chosen as a previous study indicated that some signs of sintering were observed in $\mathrm{MgB}_{2}$ samples heat-treated at this temperature [19]. Following heat-treatment, the density of the samples was then measured using the Archimedes method with propan-2-ol as the immersion medium. The hardness was measured at room temperature by Vickers indentation with a $2 \mathrm{~kg}$ load and a $10 \mathrm{~s}$ dwell time. To identify any impurity phases formed during heat-treatment, XRD was carried out on all of the samples. The increase in $\mathrm{MgO}$ content during heat-treatment was quantified by comparing the ratio of the peak areas of the $\mathrm{MgB}_{2}(110)$ and $\mathrm{MgO}(220)$ peaks in the $\theta-2 \theta$ X-ray diffraction spectrum for known standards to those of each sample, as described previously [19]. Samples were also fractured and these fracture surfaces examined using a JEOL $840 \mathrm{~F}$ scanning electron microscope with a fieldemission gun operated at $5 \mathrm{kV}$.

Magnetization measurements were carried out on powders and heat-treated samples using a Quantum Design Magnetic Property Measurement System (MPMS). MgB $_{2}$ samples were cut into small cuboids using a wire cutter and measured with the long axis of the cuboid parallel to the applied magnetic field. Measurements were made at $4 \mathrm{~K}$ and $20 \mathrm{~K}$ with an applied magnetic field of up to $7 \mathrm{~T}$, with a step size of $0.05 \mathrm{~T}$ for $0 \leq \mathrm{H}(\mathrm{T}) \leq 2$ and $-2 \leq \mathrm{H}(T)$ $\leq 0$ and of $0.2 \mathrm{~T}$ for $2 \leq \mathrm{H}(\mathrm{T}) \leq 7$ and $-7 \leq \mathrm{H}(\mathrm{T}) \leq-2$.

\section{Results and Discussion}

\subsection{Modification and Characterisation of Magnesium Diboride Powder}

A previous study has demonstrated that the measured particle size distribution in $\mathrm{MgB}_{2}$ powder varied according to the degree of dispersion [19]. For this reason particle size measurements were made of powders after drying, and of powders dried and then redispersed in propan-2-ol by ultrasonication. In addition, particle size distributions of powders which were not dried following ball milling were measured following dispersion by stirring in propan-2-ol, and following ultrasonication in propan-2-ol. Figures 2 and 3 demonstrate the huge changes in particle size distributions obtained for powders dispersed in these ways. This is due to the breakdown of agglomerates in the as-milled powder.

Figure 2 shows the particle size measurements for powders which were milled and dried prior to particle size analysis. While for samples added to the laser diffraction system as dry powders the particle size distributions were extremely varied, for the samples prepared in different atmospheres but for the same milling time the particle size distributions are fairly similar after ultrasonication in propan-2-ol.

Dramatic changes in the particle size distribution of the attrition milled powder are observed, as following ultrasonication the particle size distribution alters radically from mainly particles with diameter greater than $10 \mu \mathrm{m}$ (Figure 2a) to a distribution with a large proportion of particles with diameter less than $1 \mu \mathrm{m}$ (Figure 2b). The median particle size is given in Table 2 for each powder. In general the median particle size (indicated by the particle 
size distributions measured following ultrasonication) decreases with increasing milling time, as expected. However for powders which have undergone long ball milling times or attrition milling (a high energy milling process) this effect is masked in the particle size distributions measured for dried powders which were not dispersed as a result of severe agglomeration during the drying process. This indicates the importance of dispersion when measuring particle size distributions of magnesium diboride powders since failing to optimise this procedure can lead to misleading observations. It is also important to note that a high degree of agglomeration in the starting powder significantly limits the maximum packing density achievable in the green body, and this can in turn limit the density of the final fired bulk material. This would be also affect the final properties of powder-in-tube wires produced from $\mathrm{MgB}_{2}$ powders.

Table 2. Median particle size measured by laser diffraction on powder samples which were added to the system as dry powder, or dispersed prior to measurement in propan-2-ol by stirring or ultrasonication.

\begin{tabular}{|c|c|c|c|}
\hline \multirow[b]{2}{*}{ Sample } & \multicolumn{3}{|c|}{ Median Particle Size $(\mu \mathrm{m})$} \\
\hline & Dry Powder & Stirred Powder & Ultrasonic \\
\hline BM $1 \mathrm{~h}$ air dried & 26.8 & 24.6 & 2.9 \\
\hline $\mathrm{BM} 8 \mathrm{~h}$ air dried & 209.5 & 18.7 & 7.8 \\
\hline BM $20 \mathrm{~h}$ air dried & 17.8 & 14.5 & 3.8 \\
\hline $\mathrm{BM} 1 \mathrm{~h} \mathrm{~N}_{2}$ dried & 10.0 & 9.0 & 15.2 \\
\hline $\mathrm{BM} 8 \mathrm{~h} \mathrm{~N}_{2}$ dried & 25.4 & 205.0 & 38.5 \\
\hline BM 20h N $\mathrm{N}_{2}$ dried & 8.9 & 7.0 & 12.4 \\
\hline BM 1h air & - & 44.8 & 66.7 \\
\hline BM 8h air & - & 8.3 & 4.8 \\
\hline BM $20 \mathrm{~h}$ air & - & 3.4 & 1.2 \\
\hline $\mathrm{BM} 1 \mathrm{~h} \mathrm{~N} \mathrm{~N}_{2}$ & - & 32.7 & 5.3 \\
\hline $\mathrm{BM} 8 \mathrm{~h} \mathrm{~N}_{2}$ & - & 18.2 & 6.7 \\
\hline BM 20h N 2 & - & 5.0 & 3.7 \\
\hline Attrition Milled & 101.7 & 66.8 & 0.8 \\
\hline As-Purchased & 29.9 & 20.2 & 8.4 \\
\hline
\end{tabular}

After just $1 \mathrm{~h}$ of ball milling the particle size distribution changes (Figure 2a), with the largest peak in the distribution shifting to a lower diameter (c. 20-30 $\mu \mathrm{m}$ ) but still containing particles greater than $100 \mu \mathrm{m}$ diameter. The lower limit is already lowered to around $0.4 \mu \mathrm{m}$ compared to the as-purchased powder which had a lower particle size of around $1 \mu \mathrm{m}$ when dried (Figure 2a). However this change does not occur for powders which have been ultrasonicated prior to particle size measurement (Figure 2b), with both the as- 
purchased powder and the milled powders having lower limits of $0.2-0.3 \mu \mathrm{m}$. This indicates that the $1 \mathrm{~h}$ ball milling treatment is at least partly de-agglomerating the powder, rather than reducing the fundamental particle size. After $8 \mathrm{~h}$ ball milling, the largest particles have been broken down and but the spectrum still indicates a large volume of particles with diameter greater than $10 \mu \mathrm{m}$. After $20 \mathrm{~h}$ ball milling agglomeration similar to that for the attrition milled powder is observed in the dried powder, with a large proportion of particles greater than $100 \mu \mathrm{m}$ in diameter. After ultrasonication the particle size is reduced significantly with a peak around 2-3 $\mu \mathrm{m}$.

(a)

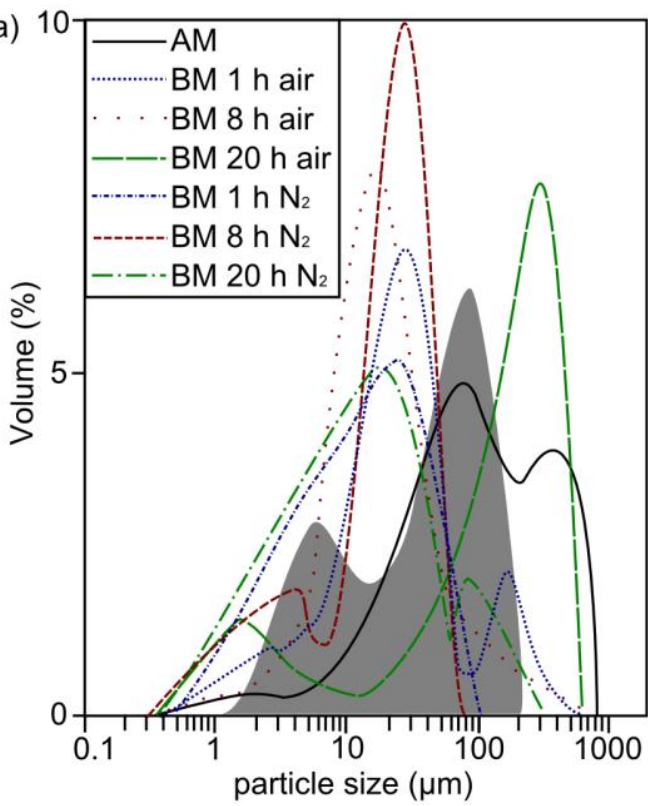

(b)

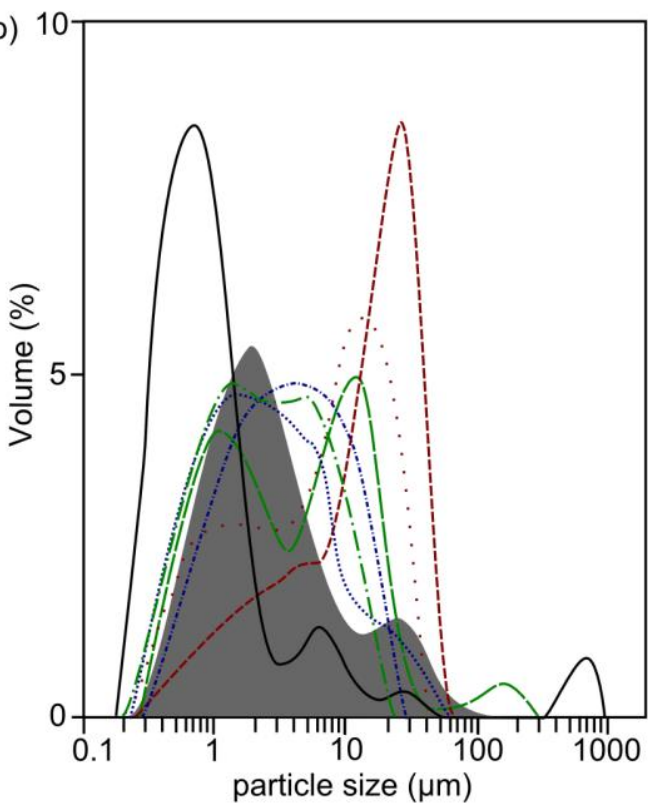

Figure 2. Particle size distribution of magnesium diboride powders packed in air or nitrogen and dried prior to particle size measurements a) Dry powders b) Powders dispersed in propan-

2-ol by ultrasonication. The shaded data indicates the particle size distribution of the aspurchased $\mathrm{MgB}_{2}$ powder dispersed in the same way.

The particle size distributions for the ball milled powders which were not dried prior to measurement are shown in Figure 3. These powders were re-dispersed by stirring or ultrasonication in propan-2-ol. For the stirred powders the particle size distributions are similar for the powders milled in nitrogen and air for each milling time, indicating that the packing environment has no effect on the milling efficiency. In general the particle size decreases with increased milling time, as expected, but in contrast to Figure 2 where the drying process caused agglomeration. The particle size distributions of powders postultrasonication (Figure 3b) are significantly different to the stirred powders (Figure 3a) due to the breakup of agglomerates. These two observations put together indicate that the agglomeration is not only caused by capillary forces and other effects during the drying process; the interparticle forces are sufficient to cause agglomeration even in propan-2-ol. The smallest median particle size is for the sample ball milled for $20 \mathrm{~h}$ and packed in air (c. $1 \mu \mathrm{m})$. 

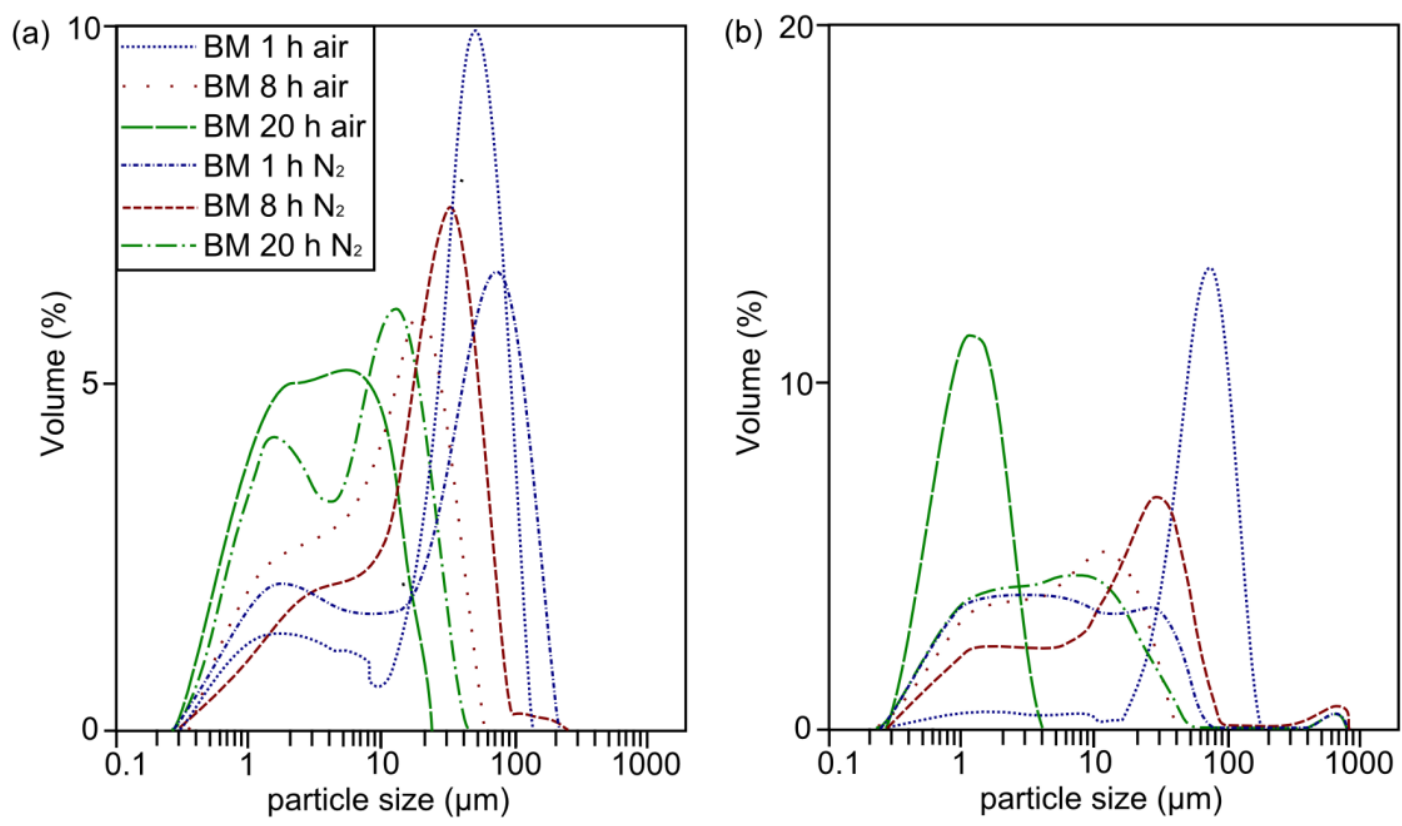

Figure 3. Particle size distribution of ball milled magnesium diboride powders packed in air and milled for 1,8 or 20 hours. Powders were not dried after milling and were dispersed for particle size measurements by a) stirring in propan-2-ol; b) ultrasonication in propan-2-ol.

XRD spectra (not shown) showed no measureable change in the content of crystalline impurity phases for all milled powders. Two alternative methods (EDX and XPS) were therefore used to establish whether any changes in composition had occurred during milling. Selected powders representing a range of processing conditions were analysed using these techniques.

Averaged EDX spectra on as-purchased, ball milled ( $8 \mathrm{~h}$ and $20 \mathrm{~h}$ in air) and attrition milled $\mathrm{MgB}_{2}$ powders indicate limited surface contamination with fluorine, zirconium and silicon contamination (Figure 4). Fluorine and silicon are common surface contaminants, particularly when samples have been in contact with plastic containers, and are observed for all samples including the as-purchased powder. The zirconium originates from the YSZ milling media. No peaks due to zirconia were found in the XRD spectra indicating that the total phase content of zirconia is low (below 2\%). Spectra taken from ball milled powders indicate lower levels of zirconium contamination compared to attrition milling. For the attrition milled powder the $\mathrm{Zr}$ peaks are significantly above the noise level in the spectrum whereas for the ball milled powders they are difficult to make out against the background.

a)

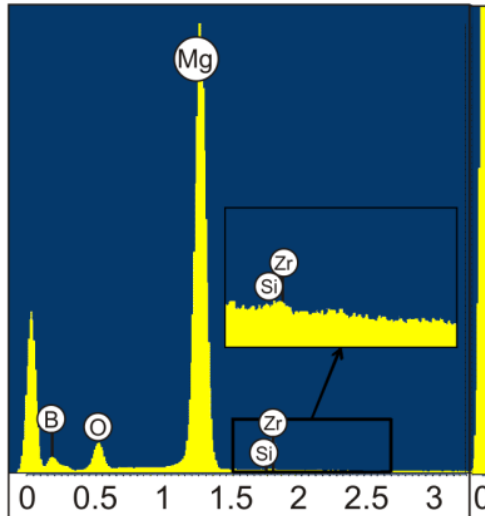

b)

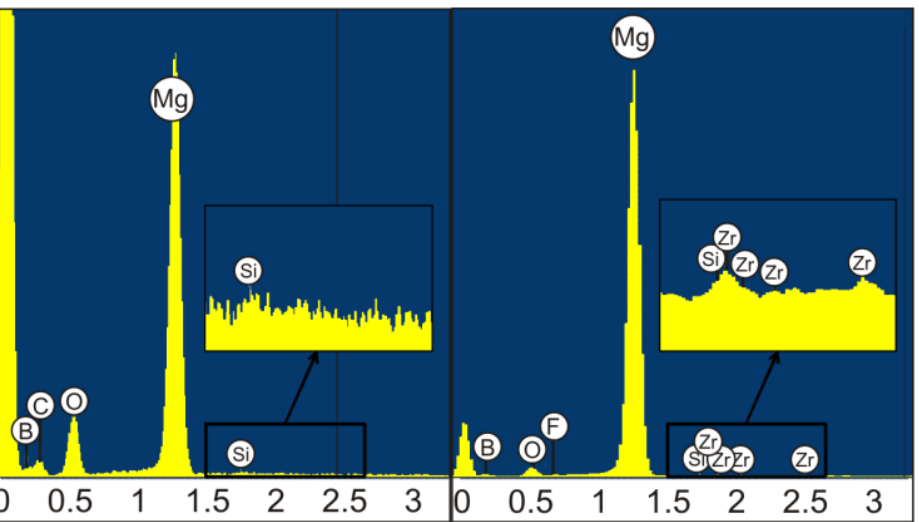

Figure 4. EDX Spectra of $\mathrm{MgB}_{2}$ powders packed in air and milled in propan-2-ol (a) Ball milled 8 hours (b) Ball milled 20 hours (c) Attrition milled. Intensities are not normalised. 
The EDX compositions are corroborated by analysis of the XPS spectra. These indicate that the surfaces of the powder particles contain carbon, oxygen, fluorine, nitrogen, zirconium, silicon, boron and magnesium. Quantitative analysis of the elemental composition of the powder surfaces was carried out and is shown in Table 3 for each powder. The highest level of zirconium contamination is found for the attrition milled powder. In addition, narrow energy range spectra were taken in the region of the B 1s and Mg 2p XPS peaks (Figure 5). Examining the shape and position of these peaks reveals that boron is present in all spectra in the oxidation states characteristic of both $\mathrm{B}_{2} \mathrm{O}_{3}$ (peak at $\sim 192-3 \mathrm{eV}$ ) and $\mathrm{MgB}_{2}$ (peak at $\sim 186$ $\mathrm{eV})[29,30]$. There are additional peaks in the attrition milled spectrum at approximately 182.8 and $184.6 \mathrm{eV}$ which are due to zirconium. The sample ball milled for 20 hours has the highest surface $\mathrm{B}_{2} \mathrm{O}_{3}$ content. The $\mathrm{Mg} 2 \mathrm{p}$ XPS spectrum appears to contain one broad asymmetric peak for all powders; however two of the possible candidates are very close in energy $\left(\sim 49 \mathrm{eV}=\mathrm{MgB}_{2}, \sim 51 \mathrm{eV}=\mathrm{MgO}\right)[29,30]$ indicating that the powder surfaces are actually a mixture of $\mathrm{MgB}_{2}$ and $\mathrm{MgO}$.

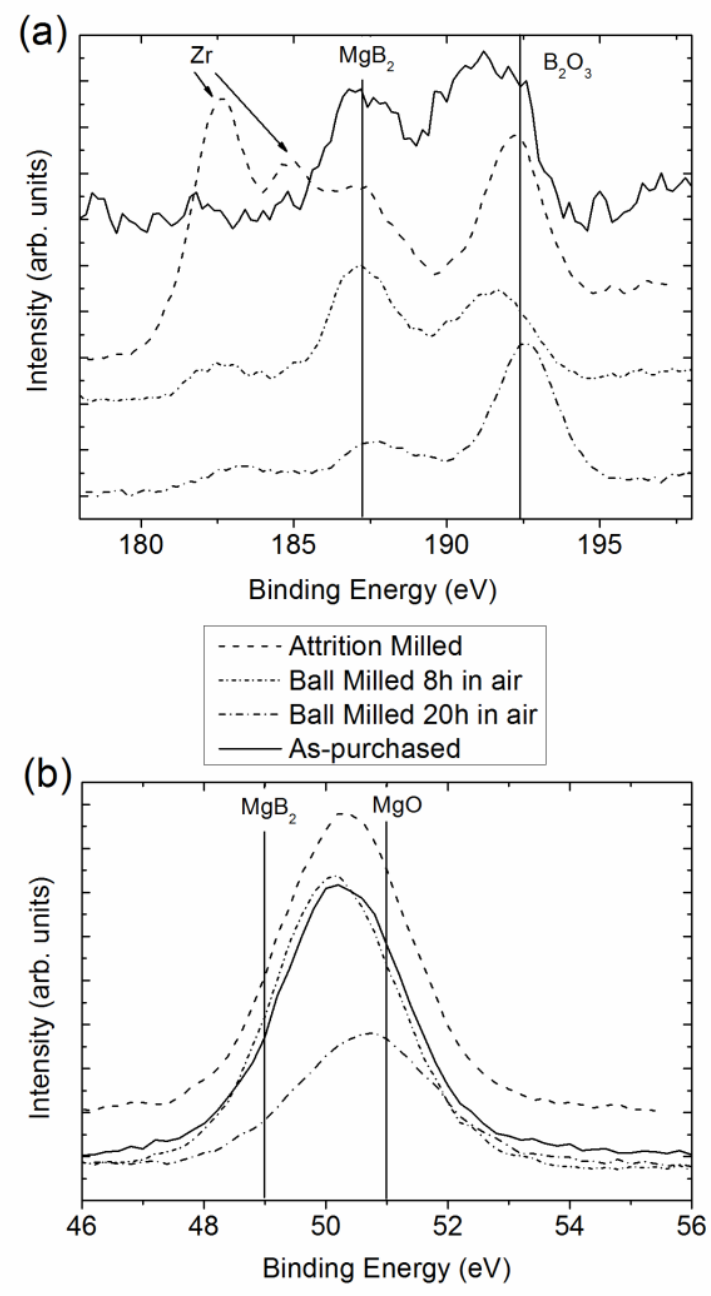

Figure 5. Detailed XPS spectra on selected $\mathrm{MgB}_{2}$ powders (a) Boron 1s region (b)

Magnesium 2p region (spectra are overlaid and charge shift compensated). Vertical lines indicate the approximate positions of peaks for the labelled species from Prince et al [29] and the NIST XPS Database [30]. 
Table 3. Surface elemental contents (in at.\%) measured from XPS spectra.

\begin{tabular}{cccccccccc}
\hline & $\mathrm{Mg}$ & $\mathrm{B}$ & $\mathrm{O}$ & $\mathrm{C}$ & $\mathrm{F}$ & $\mathrm{N}$ & $\mathrm{Zr}$ & $\mathrm{Si}$ & $\mathrm{Ar}$ \\
\hline $\begin{array}{c}\text { As- } \\
\text { purchased }\end{array}$ & 14.2 & 10.8 & 33.1 & 34.7 & 4.0 & 2.5 & 0.0 & 0.7 & 0.1 \\
\hline $\begin{array}{c}\text { Ball Milled } \\
8 \mathrm{~h}\end{array}$ & 11.3 & 10.3 & 30.4 & 43.1 & 2.8 & 1.8 & 0.1 & 1.3 & $0 . .0$ \\
\hline $\begin{array}{c}\text { Ball Milled } \\
20 \mathrm{~h}\end{array}$ & 5.1 & 7.1 & 25.5 & 59.1 & 1.0 & 0.6 & 0.0 & 1.4 & 0.2 \\
\hline $\begin{array}{c}\text { Attrition } \\
\text { milled }\end{array}$ & 11.4 & 10.3 & 39.8 & 35.5 & 1.7 & 0.7 & 0.6 & 0.1 & 0.1 \\
\hline
\end{tabular}

Compositional analyses indicate some surface oxidation and $\mathrm{ZrO}_{2}$ contamination, particularly for the powder ball milled for $20 \mathrm{~h}$ and the attrition milled powder. Carbon contamination on the surface of the powders was particularly high for the ball milled powders, probably due to the long exposure to propan-2-ol. However it is important to note that these the bulk of these powders consists primarily of $\mathrm{MgB}_{2}$, as indicated from the XRD spectra.

Powders were also examined using SEM. In general the powder appeared similar to the as-purchased powder, consisting of a mixture of particles and agglomerates with a range of sizes (examples from the attrition milled powder are given in Figure 6a-c). However in the attrition milled powder only a few particles with non-typical morphology were observed (Figure 6d). These are thought to result from impurities precipitating out of the propan-2-ol during drying.

The above results of characterizing the milled powders demonstrate the range of properties which are affected by the milling process. Powders with a range of particle size distribution shape and ranges have been produced. The impurity content of the milled powders varies both in the extent of contamination and the particular impurities introduced, which include zirconia from the milling media in agreement with Chen et al [15]. However the powders still consist mostly of crystalline $\mathrm{MgB}_{2}$ particles. In addition, observations of the powder particles by scanning electron microscopy indicated only limited morphological differences between the as-purchased powder and the milled powders. The effect of differences in the milled powders on the properties of bulk $\mathrm{MgB}_{2}$ produced from each powder was then examined. 

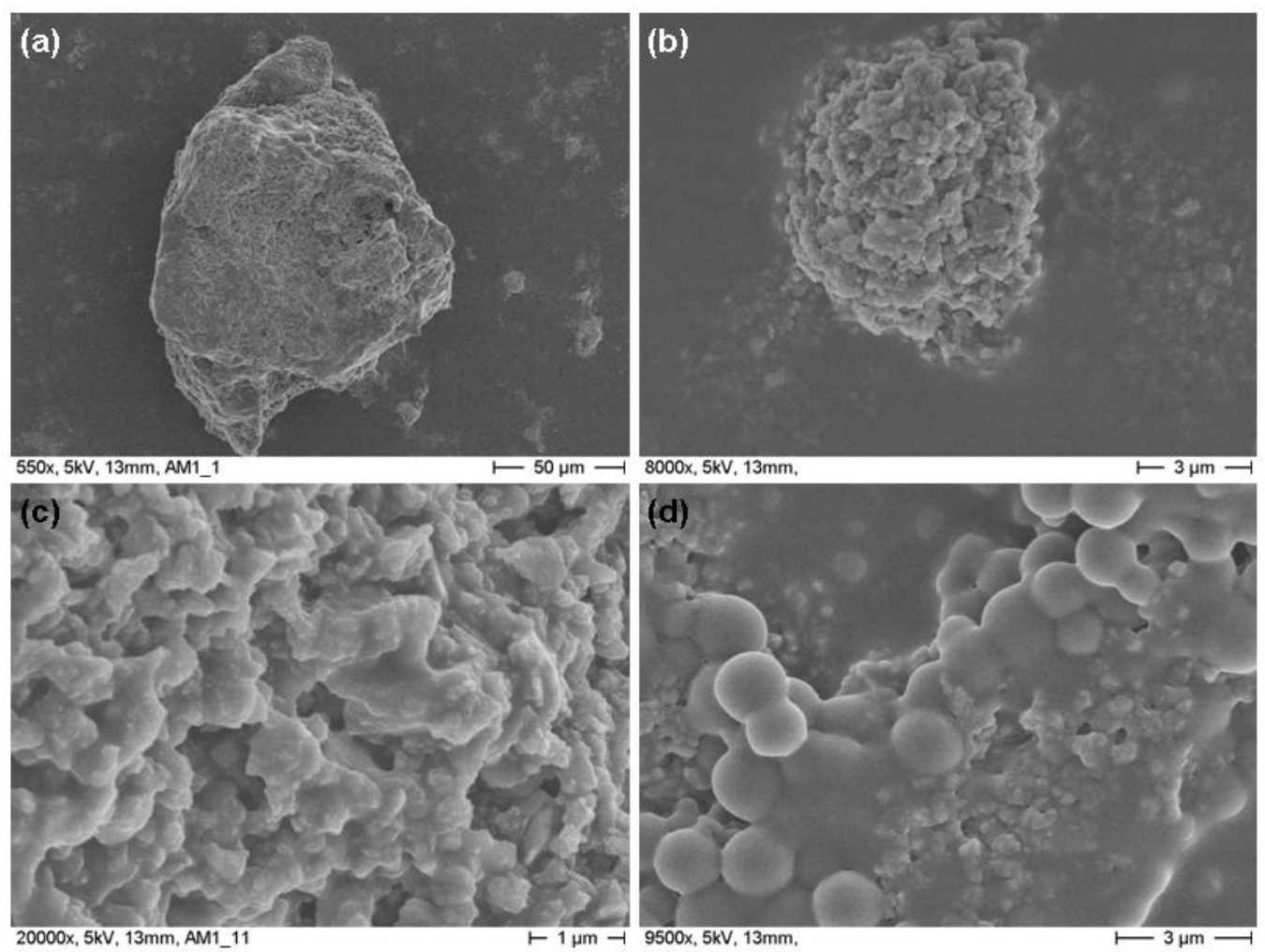

Figure 6. Typical SEM images of attrition milled powder particles.

\subsection{Magnesium Diboride Produced from Modified Powders}

Powders were uniaxially pressed and heat-treated under ambient pressure at peak temperatures of $950{ }^{\circ} \mathrm{C}$ to $1100{ }^{\circ} \mathrm{C}$ in flowing argon. Details of processing conditions are summarized in Table 3, along with measured physical properties: the relative density (compared to the theoretical maximum), Vickers hardness measured with $2 \mathrm{~kg}$ load, and the $\mathrm{MgO}$ content determined from XRD $\theta-2 \theta$ spectra. For comparison, the same data for the samples produced from as-purchased Alfa Aesar powder and reported earlier [19] are included.

In general, using milled powders decreases the density of the samples. This is likely to be due to the milling processes producing powders with narrower particle size distributions, which are expected to pack less efficiently than powders with wide particle size distributions in which smaller particles can fit in the interstices between larger particles [22].

The $\mathrm{MgO}$ content measured from XRD spectra is generally higher for samples heattreated at the higher temperature and is particularly high for those prepared from attrition milled powder. The $\mathrm{MgO}$ content is consistently lower for samples produced from powders handled only in nitrogen rather than air, apart from those which were ball milled for $20 \mathrm{~h}$. This may be due to reaction of $\mathrm{MgB}_{2}$ surfaces with air during heat-treatment due to the creation of new surfaces by the breaking up of particles by long-duration milling. For the powders milled for the same duration but packed in air, this reaction would be expected to occur during or after milling. In addition to the characteristic peaks used to quantify the $\mathrm{MgO}$ content in Table 3, peaks due to $\mathrm{MgB}_{4}$ were observed in some of the $\theta-2 \theta$ XRD spectra. Selected representative spectra for $2 \theta$ ranges including peaks due to $\mathrm{MgO}$ and $\mathrm{MgB}_{4}$ are shown in Figure 7. $\mathrm{MgB}_{4}$ peaks are largest and most prevalent in powders with high $\mathrm{MgO}$ contents, yet were not present in the XRD spectra of the starting powder, indicating that $\mathrm{MgB}_{2}$ breaks down to form $\mathrm{MgO}$ and $\mathrm{MgB}_{4}$ during heat treatment, in agreement with observations by Lezza et al [31]. $\mathrm{MgB}_{4}$ was not detected in every spectrum, while measurable levels of $\mathrm{MgO}$ were observed in all spectra. In contrast to this work, Gao et al [32] observed complete amorphization of $\mathrm{MgB}_{2}$ powder after $20 \mathrm{~h}$ milling in air with steel balls, 
demonstrated by the disappearance of crystalline peaks in the $\theta-2 \theta$ XRD spectrum with increasing milling time, indicating that the milling methods used by different research groups should not necessarily be expected to produce similar powders, even when milling durations are identical.

Table 3. Processing conditions and physical properties of $\mathrm{MgB}_{2}$ samples.

\begin{tabular}{cccccc}
\hline Processing & $\begin{array}{c}\text { Temperature } \\
\left({ }^{\circ} \mathrm{C}\right)\end{array}$ & $\begin{array}{c}\text { Processing } \\
\text { Atmosphere }\end{array}$ & $\begin{array}{c}\text { Relative } \\
\text { Density }\end{array}$ & $\begin{array}{c}\text { Vickers } \\
\text { Hardness } \\
(\mathrm{HV} / 2)\end{array}$ & $\begin{array}{c}\text { MgO Content } \\
\text { (from XRD) }\end{array}$ \\
\hline Attrition & 950 & Air & $56 \%$ & 141 & $31 \%$ \\
\hline Attrition & 1100 & Air & $58 \%$ & 94 & $37 \%$ \\
\hline Ball 1 h & 950 & Air & $61 \%$ & 63 & $9 \%$ \\
\hline Ball 1 h & 950 & $\mathrm{~N}_{2}$ & $60 \%$ & 68 & $6 \%$ \\
\hline Ball $8 \mathrm{~h}$ & 950 & Air & $56 \%$ & 123 & $23 \%$ \\
\hline Ball 8h & 950 & $\mathrm{~N}_{2}$ & $58 \%$ & 72 & $7 \%$ \\
\hline Ball 20 h & 950 & Air & $61 \%$ & 80 & $11 \%$ \\
\hline Ball 20 h & 950 & $\mathrm{~N}_{2}$ & $50 \%$ & 121 & $23 \%$ \\
\hline Ball 1 h & 1100 & Air & $60 \%$ & 157 & $12 \%$ \\
\hline Ball 1 h & 1100 & $\mathrm{~N}_{2}$ & $65 \%$ & 104 & $9 \%$ \\
\hline Ball $8 \mathrm{~h}$ & 1100 & Air & $57 \%$ & 175 & $25 \%$ \\
\hline Ball $8 \mathrm{~h}$ & 1100 & $\mathrm{~N}_{2}$ & $55 \%$ & 84 & $10 \%$ \\
\hline Ball 20 h & 1100 & Air & $58 \%$ & 118 & $23 \%$ \\
\hline Ball 20 h & 1100 & $\mathrm{~N}_{2}$ & $51 \%$ & 107 & $29 \%$ \\
\hline None & 950 & - & $70 \%$ & 52 & $5 \%$ \\
\hline None & 1100 & - & $65 \%$ & 89 & $7 \%$ \\
\hline
\end{tabular}

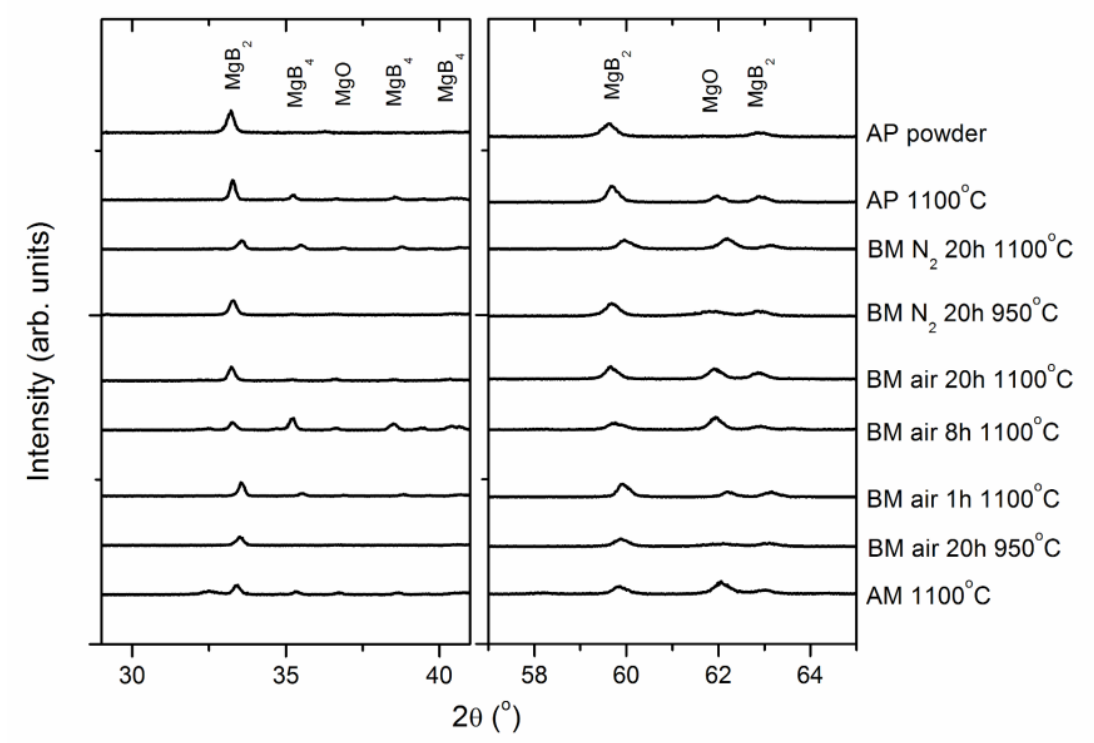

Figure 7. Typical XRD spectra of sintered $\mathrm{MgB}_{2}$ samples $(\mathrm{AP}=$ as-purchased, $\mathrm{BM}=$ ball milled, $\mathrm{AM}=$ attrition milled). Temperatures indicated are the peak heat-treatment temperatures for each sample and the spectrum for the starting powder is included for comparison.

Previously we reported a correlation between density and hardness for $\mathrm{MgB}_{2}$ samples over a wide range of both variables [33]. For these new samples no such correlation could be established. The reason for this is illustrated in Figure 8, which shows independent 
correlations between density and $\mathrm{MgO}$ content (Figure 8a) and between hardness and $\mathrm{MgO}$ content (Figure 8b). Each set of data has been fitted using second order polynomial regressions. The density vs. $\mathrm{MgO}$ content curve has a minimum at approximately $25 \mathrm{wt} . \%$ $\mathrm{MgO}$, while the hardness vs. $\mathrm{MgO}$ content has a maximum at approximately the same value. Therefore when hardness is plotted against density, the data appear to be scattered and uncorrelated. The shape of these curves indicates that at low concentrations the $\mathrm{MgO}$ plays a part in increasing the hardness by bonding adjacent particles. At higher $\mathrm{MgO}$ content the hardness decreases as the microstructure becomes increasing multi-phase in nature and the $\mathrm{MgB}_{4}$ content increases, the hardness then being a combination of the hardness of $\mathrm{MgB}_{2}$ and that of the impurity phases. The Vickers hardness of dense polycrystalline $\mathrm{MgO}$ is around 930 $\mathrm{HV}$ [34] while that of hot isostatically pressed dense polycrystalline $\mathrm{MgB}_{2}$ has been measured at 1060-1200 $\mathrm{HV}$ [35]. The hardness of $\mathrm{MgB}_{4}$ has not been determined. In addition to the effect of multiple phases, macroscopic hardness measurements are affected by the porosity and connectivity of the samples, as ceramic materials demonstrate greater resistance to indentation as the porosity decreases [36]. In this case the moderate increase in impurity phase levels may bond the particles together, giving increased resistance to indentation. As the impurity level increases to higher levels the material becomes increasingly two-phase in nature and the resistance to indentation decreases again.
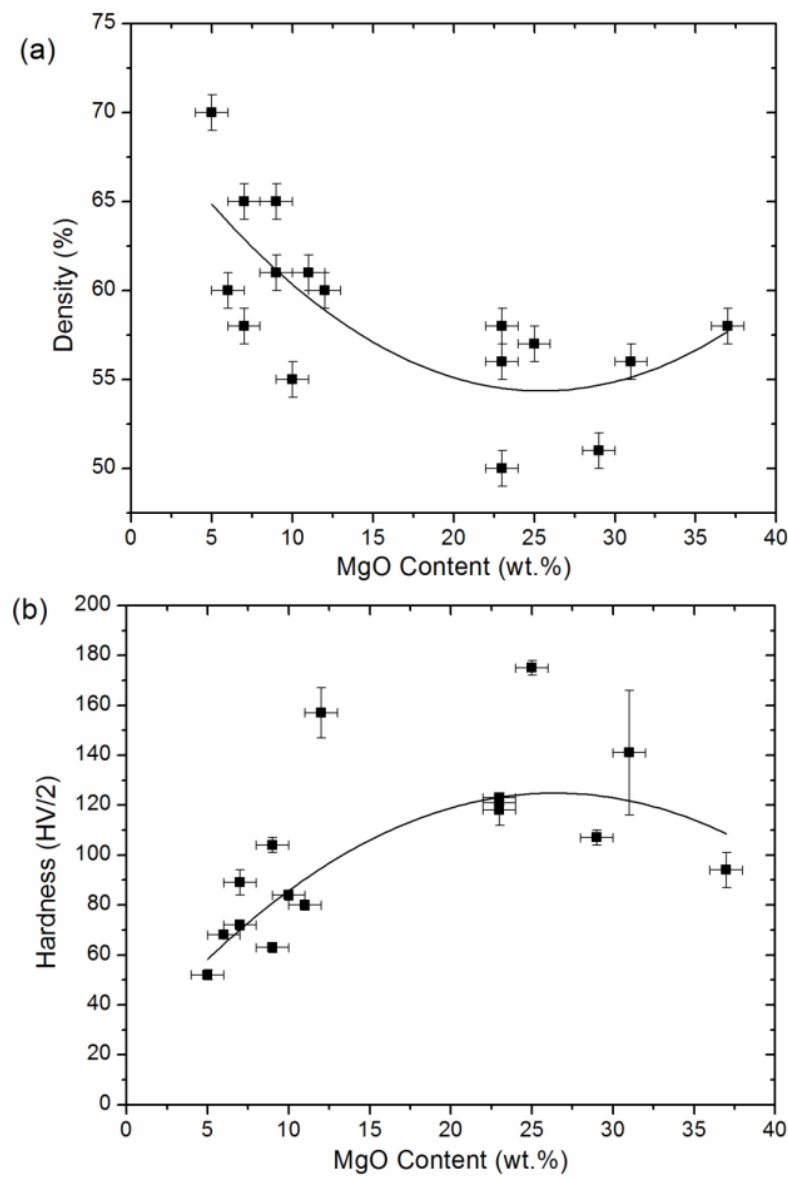

Figure 8. (a) $\mathrm{MgO}$ content versus hardness for $\mathrm{MgB}_{2}$ samples (b) $\mathrm{MgO}$ content versus density for bulk samples. Best fit lines were determined by a weighted least-squares regression giving second order polynomial curves in both cases.

Samples were fractured and examined using SEM. The fracture surfaces of the samples heat-treated at $950{ }^{\circ} \mathrm{C}$ (not shown) showed no signs of sintering, and no significant differences were apparent between these samples prepared from different powders. Figure 9 shows fracture surfaces of selected $\mathrm{MgB}_{2}$ samples heat-treated at $1100{ }^{\circ} \mathrm{C}$, with an equivalent 
fracture surface of a sample produced from as-purchased powder included for comparison. More connectivity between particles is apparent for all the samples heat-treated at $1100{ }^{\circ} \mathrm{C}$ which is indicative of increased sintering. Dense regions containing occluded porosity were visible on the fracture surface of the sample produced from attrition milled powder (Figure 9d) though other regions appeared more similar to the other samples heat-treated at this temperature - connected grains but with significant porosity. These denser regions were also seen (though much less frequently) in the sample produced from powder ball milled for $20 \mathrm{~h}$. This clearly indicates that decreasing the particle size by high energy or long duration milling allows more sintering to occur. However the density of these samples is still significantly lower than the density of samples produced by pressure-assisted methods (typically greater than $90 \%$ dense) [25], indicating that pressure-assisted heat-treatment is still necessary to obtain truly dense $\mathrm{MgB}_{2}$. In addition increasing the heat-treatment temperature and/or duration is expected to lead to a greater proportion of dense regions in the $\mathrm{MgB}_{2}$ samples, but may also result in higher levels of impurity phases.
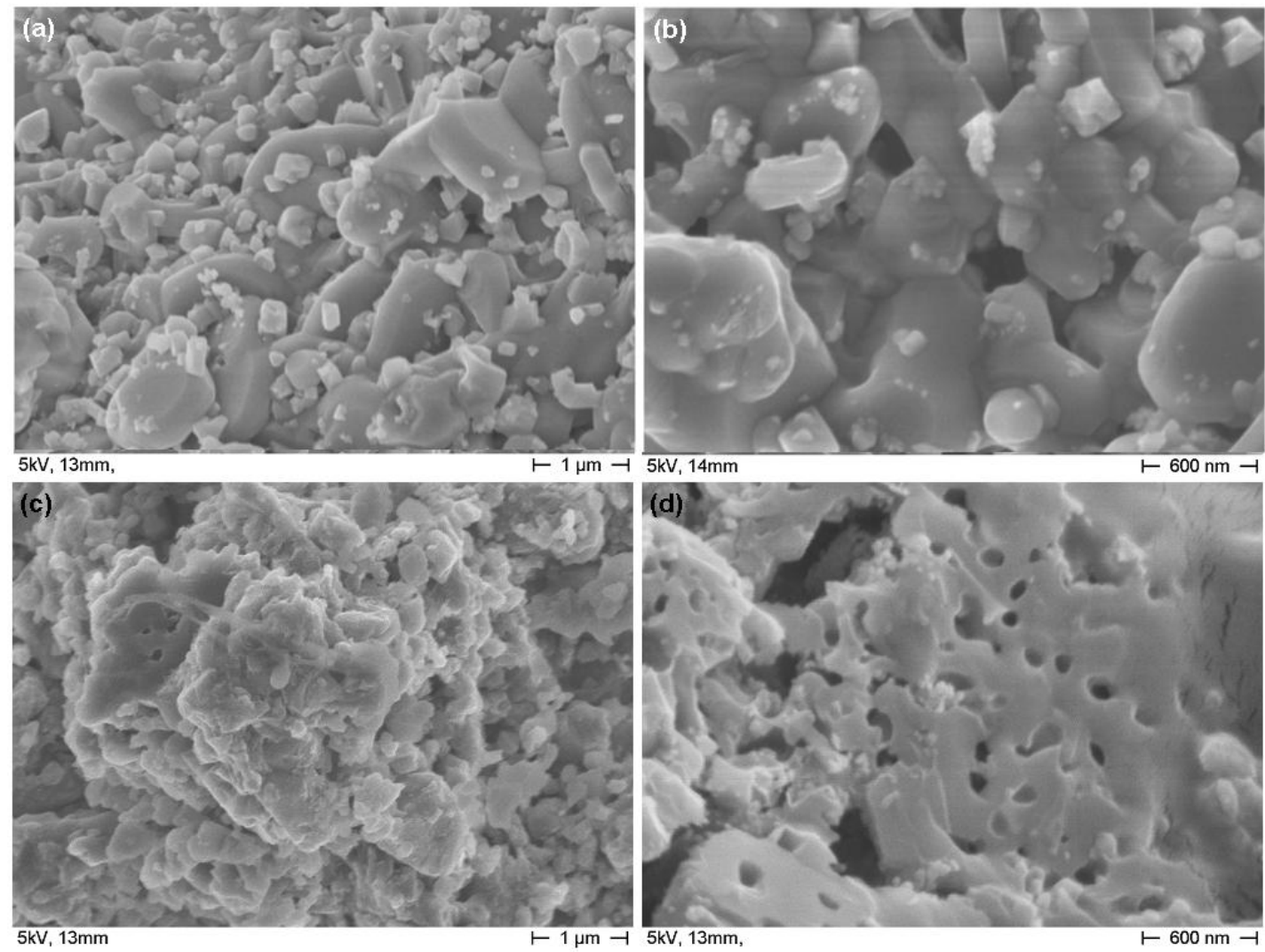

Figure 9. SEM images of fracture surfaces of selected $\mathrm{MgB}_{2}$ samples heat treated at $1100{ }^{\circ} \mathrm{C}$. (a) as-purchased powder, (b) ball milled in propan-2-ol for $8 \mathrm{~h}$, handled in air, (c) ball milled in propan-2-ol for $20 \mathrm{~h}$, handled in air, (d) attrition milled in propan-2-ol for $2 \mathrm{~h}$, handled in air. Samples produced from magnesium diboride loaded under nitrogen and ball milled in propan-2-ol showed similar features to those from powders loaded in air.

The superconducting properties of the starting powders and pressed and heat-treated samples were measured by the magnetization method at $4 \mathrm{~K}$ and $20 \mathrm{~K} . J_{c, m a g}$ vs. $H$ curves were calculated using the Bean Model [37] (Figure 10). There was no intention to produce materials with high $J_{c, \text { mag }}$; rather these measurements were used to rank the samples produced with well controlled differences in processing and to correlate $J_{c, m a g}$ performance with the modifications made to the starting powder. The sample produced from powder ball milled for $20 \mathrm{~h}$ has significantly lower $J_{c, \text { mag }}$ than the other samples, even in low fields. The $J_{c, \text { mag }}$ performance of the sample produced from attrition milled powder was similar at low fields to that produced from as-purchased $\mathrm{MgB}_{2}$ powder, though significantly higher (by one order of 
magnitude) at $5 \mathrm{~T}$. At $20 \mathrm{~K} J_{c, \text { mag }}$ of all the samples falls below $10^{3} \mathrm{~A} \mathrm{~cm}^{-2}$ by $3 \mathrm{~T}$. The sample produced from powder ball milled for $8 \mathrm{~h}$ has the highest $J_{c, m a g}$ at $4 \mathrm{~K}$ and in low field; at higher field the sample from attrition milled powder has better performance. These are about an order of magnitude lower than the values reported by Flukiger et al [3] for $J_{c, \text { trans }}$ measurements at $4.2 \mathrm{~K}, 5 \mathrm{~T}$ on PIT tapes produced from milled powders; however their tapes were prepared at a lower heat-treatment temperature and it is well-known that measurements by the transport method often differ from those by magnetization methods. It is apparent that by using high energy attrition milling rather than ball milling a small particle size can be attained without loss of superconductivity, given that the particle size range of the attrition milled powder was similar to that ball milled for $20 \mathrm{~h}$. We speculate that this change in superconducting properties for the material ball milled for $20 \mathrm{~h}$ may be due to an increase in $\mathrm{B}_{2} \mathrm{O}_{3}$ and $\mathrm{MgO}$ content in the powder due to increased decomposition of $\mathrm{MgB}_{2}$ with milling time, as shown by the XPS results (Figure 5).
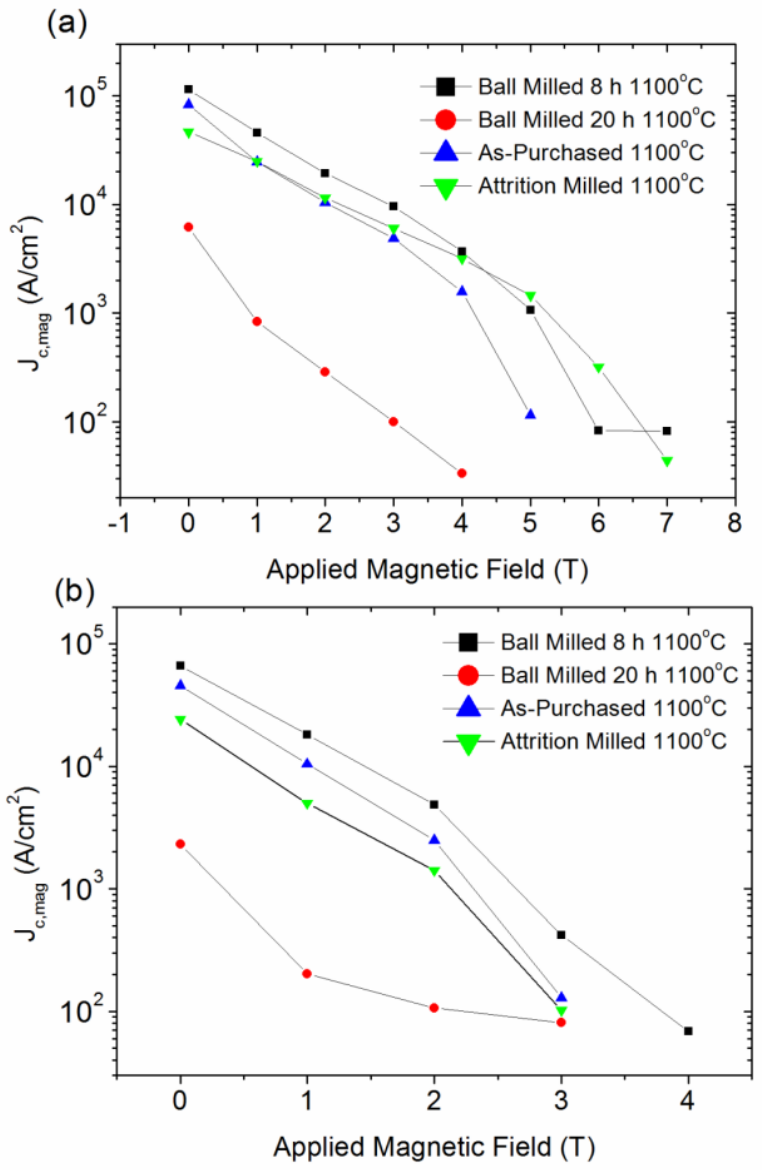

Figure 10. Critical current density curves for selected samples measured at (a) $4 \mathrm{~K}$, (b) $20 \mathrm{~K}$. Calculated using the Bean model [37] from measurements made by the magnetization method.

It is evident from these results that the use of milled $\mathrm{MgB}_{2}$ powders to produce $\mathrm{MgB}_{2}$ samples affects the hardness, density, impurity content, microstructure and superconducting behaviour. The specific correlations between these properties are complex. For instance, long ball milling durations produce powders with similar particle size distributions to high energy, short duration milling, but the superconducting behaviour is very different. This behaviour appears to contradict the findings of Braccini et al [16] who correlated milling time with $J_{c, \text { mag. }}$. However they do not specify the milling duration or the milling method used, so it is not possible to directly compare their results with those of this work. The influence of the 
duration of propan-2-ol exposure should be further examined as it may be the origin of these differences.

\section{Conclusions}

Alfa Aesar $\mathrm{MgB}_{2}$ was milled in propan-2-ol using both high energy attrition milling and ball milling for various durations. The average particle size decreased with milling duration for ball milling, and the impurity levels measured by XPS and EDX increased. In general the attrition milled powder behaved similarly to the powders ball milled for the longest time. Particle size measurements of powders which were dispersed prior to measurement by ultrasonic methods rather than simply by adding to the laser diffraction system had significantly different particle size distributions, indicating the severe agglomeration in these powders. This limits the packing density of both the green body, and the final heat-treated samples.

Bulk $\mathrm{MgB}_{2}$ samples were produced from these powders by uniaxial pressing and heat treatment at peak temperatures up to $1100{ }^{\circ} \mathrm{C}$. These were compared to similar samples produced from as-purchased $\mathrm{MgB}_{2}$ powder. Hardness and density were compared to $\mathrm{MgO}$ content assessed from $\theta-2 \theta$ XRD spectra for each sample and a clear correlation established. Samples produced from powders which were attrition milled or ball milled for long durations had particularly high $\mathrm{MgO}$ content coupled with additional $\mathrm{MgB}_{4}$ impurities which had a strong influence on density and hardness values. The morphology of the fracture surfaces was examined using SEM and indicated increased connectivity in the samples heat-treated at 1100 ${ }^{\circ} \mathrm{C}$, along with isolated regions of sintered particles in the sample produced from attrition milled powder. These microstructural features were similar to those seen for samples produced from the same powder using a pressure-assisted sintering method [19] and suggest that sintering can be increased by careful choice of milling process.

The superconducting behaviour was examined by the magnetization method on both powders and bulk samples and the results indicated that superconductivity was suppressed in powders prepared by ball milling for both $8 \mathrm{~h}$ and $20 \mathrm{~h}$. Following heat treatment at $1100{ }^{\circ} \mathrm{C}$, superconductivity was restored in the sample produced from powder ball milled for $8 \mathrm{~h}$, but not for that from powder ball milled for $20 \mathrm{~h}$. This is likely to be due to increased nonsuperconducting impurity phase $\left(\mathrm{B}_{2} \mathrm{O}_{3}\right.$ and $\left.\mathrm{MgO}\right)$ content in the powder milled for long periods due to reaction of freshly exposed $\mathrm{MgB}_{2}$ particle surfaces with air. Overall the superconducting performance was improved by using powders which were either ball milled for $8 \mathrm{~h}$ or attrition milled for $2 \mathrm{~h}$, especially in higher magnetic fields. The powder processing prior to final heat treatment clearly has a significant influence on the final superconducting properties, and improvements of orders of magnitude can be achieved, but further work would be required to determine the optimum combination of milling technique and sintering parameters to achieve the best $J_{c}$ values.

\section{Acknowledgements}

CEJD gratefully acknowledges funding from the EPSRC through the University of Oxford Department of Materials 2004 Doctoral Training Grant. We are grateful to the EPSRC Engineering Instrument Pool for the loan of the Malvern Mastersizer S laser diffraction system.

\section{References}

[1] Nagamatsu J, Nakagawa N, Muranaka T, Zenitani Y and Akimitsu J 2001 Nature 41063

[2] Buzea C and Yamashita T 2001 Supercond. Sci. Technol. 14 R115

[3] Flukiger R, Suo H L, Musolino N, Beneduce C, Toulemonde P and Lezza P 2003 Physica C 385286

[4] Goldacker W, Schlachter S I, Liu B, Obst B and Klimenko E 2004 Physica C 40180

[5] Zhou S, Pan A V, Liu H and Dou S 2002 Physica C 382349

[6] Penco R and Grasso G 2007 IEEE Trans. Appl. Supercond. 172291 
[7] Columbus Superconductors SpA Website http://www.columbussuperconductors.com. Consulted on 5th January 2010.

[8] Malagoli A, Braccini V, Bernini C, Romano G, Vignolo M, Putti M and Ferdeghini C 2010 Supercond. Sci Technol. 23025032

[9] Braccini V, Malagoli A, Tumino A, Vignolo M, Bernini C, Fanciulli C, Romano G, Tropeano M, Siri A S and Grasso G 2007 IEEE Trans. Appl. Supercond.17 2766

[10] Kováč P, Hušek I, Melišek T, Grivel J C, Pachla W, Štrbík V, Diduszko R, Homeyer J and Andersen N H 2004 Supercond. Sci. Technol. 17 L41

[11] Flukiger R, Lezza P, Beneduce C, Musolino N and Suo H L 2003 Supercond. Sci. Technol. 16264

[12] Senkowicz B J, Giencke J E, Patnaik S, Eom C B, Hellstrom E E and Larbalestier D C 2005 Applied Physics Letters 86202502

[13] Grovenor C R M, Goodsir L, Salter C J, Kovac P and Husek I 2004 Supercond. Sci. Technol. 17479

[14] Senkowicz B J, Perez Moyet R, Mungall R J, Hedstrom J, Uwakweh O N C, Hellstrom E E and Larbalestier D C 2006 Supercond. Sci. Technol. 191173

[15] Chen S K, Glowacki B A, Macmanus-Driscoll J L, Vickers M E and Majoros M 2004 Supercond. Sci. Technol. 17243

[16] Braccini V, Nardelli D, Penco R and Grasso G 2007 Physica C 456209

[17] Vignolo M et al. 2008 IEEE Trans. Appl. Supercond.18 1175

[18] Romano G, Vignolo M, Braccini V, Malagoli A, Bernini C, Tropeano M, Fanciulli C,

Putti M and Ferdeghini C 2009 IEEE Trans. Appl. Supercond. 192706

[19] Dancer C E J, Mikheenko P, Bevan A, Abell J S, Todd R I and Grovenor C R M 2009 J.

Eur. Ceram. Soc. 291817

[21] Pryor E 1955 An Introduction to Mineral Dressing (London: Mining Publications)

[21] Aswal D K, Muthe K P, Singh A, Sen S, Shah K, Gupta L C, Gupta S K and Sahni V C 2001 Physica C 363208

[22] Reed J 1995 Principles of Ceramic Processing (New York: Wiley-Interscience)

[23] Velamakanni B V and Fuerstenau D W 1993 Powder Technology 7511

[24] Shirley D A 1972 Physical Review B 54709

[25] 1990 Practical Surface Analysis vol 1, ed D Briggs and M P Seah (Chichester: Wiley)

[26] 2003 Surface Analysis by Auger and X-Ray Photoelectron Spectroscopy ed D Briggs and J T Grant (Chichester: IM Publications) p 44

[27] Grasso G, Malagoli A, Modica M, Tumino A, Ferdeghini C, Siri A S, Vignola C, Martini L, Previtali V and Volpini G 2003 Supercond. Sci. Technol. 16271

[28] Kovac P, Husek I and Melisek T 2002 Supercond. Sci. Technol. 151340

[29] Prince K C, Feyer V, Tadich A, Thomsen L and Cowie B 2009 Journal of Physics: Condensed Matter 21405701

[30] NIST X-ray Photoelectron Spectroscopy Database, Version 3.5 (National Institute of Standards and Technology, Gaithersburg, 2003); http://srdata.nist.gov/xps/

[31] Lezza P, Gladyshevskii R, Senatore C, Cusanelli G, Suo H L and Flukiger R 2005 IEEE Transactions on Applied Superconductivity 153196

[32] Gao Y D, Ding J, Rao G V S, Chowdari B V R, Sun W X and Shen Z X 2002 Phys. Stat. Sol. 191548

[33] Dancer C E J, Prabhakaran D, Başoğlu M, Yanmaz E, Yan H, Reece M, Todd R I and Grovenor C R M 2009 Supercond. Sci. Technol. 200922095003

[34] Lawn B R and Marshall D B 1979 Journal of the American Ceramic Society 62347

[35] Indrakanti S S, Nesterenko V F, Maple M B, Frederick N A, Yuhasz W H and Li S 2001

Philosophical Magazine Letters 81849

[36] Mukhopadhyay A, Datta S and Chakraborty D 1991 Ceramics International 17 121-127

[37] Bean C 1964 Reviews of Modern Physics 3631 